DOI: http://dx.doi.org/10.5965/223811711642017449

\title{
Efeito do genótipo no enraizamento e aclimatação de estacas semilenhosas de porta enxertos de pessegueiro
}

\author{
Effect of genotype on rooting and acclimatization of semihardwood cutting of peach rootstocks
}

\author{
Gabriela Gerhardt da Rosa ${ }^{{ }^{*}}$, Ilisandra Zanandrea ${ }^{2}$, Newton Alex Mayer ${ }^{3}$ e Valmor João Bianchi ${ }^{1}$
}

Submissão: 02/03/2017 / Aceite: 19/03/2017

\section{RESUMO}

O objetivo deste trabalho foi avaliar o potencial de enraizamento e aclimatação de estacas semi-lenhosas de diferentes porta enxertos de Prunus spp. (I-93-38, I-93-27, I-67-57-14, I-67-55-13) e Prunus persica (I-67-54-12), ambos de origem norte americana. Estacas semilenhosas foram preparadas com $15 \mathrm{~cm}$, mantendo um par de folhas inteiras na porção apical, acondicionadas em bandejas contendo vermiculita fina e mantidas sob nebulização intermitente por 50 dias. As estacas aptas ao transplantio foram colocadas em citropotes, contendo $2 \mathrm{~L}$ de substrato comercial Carolina ${ }^{\circledR}$ e mantidos em aclimatação por 60 dias. Observou-se que, a porcentagem de estacas enraizadas foi maior para o genótipo I-93-27 (66,66\%), não diferindo dos genótipos I-67-55-13, I-67-54-12 e I-67-57-14, com 57,77\%, 52,22\% e 44,44\% de estacas enraizadas, respectivamente, nesta cultivar também se registrou o comprimento médio das três maiores raízes $(4,74 \mathrm{~cm})$, para o número médio de raízes por estaca, os maiores valores foram observados nos genótipos I-93-27 (20,35) e I-67-57-14 (23,65). Verificou-se também que a porcentagem média de estacas transplantadas e aclimatadas foi maior para o genótipo I-93-27 (72,22\%) em relação aos demais. O genótipo I-67-55-13 apresentou melhores resultados para todas as variáveis analisadas, e, maior número de plantas estabelecidas após a aclimatação.

\section{PALAVRAS-CHAVES: Prunus persica,} enraizamento, estaca semilenhosa, ácido indolbutírico.

\footnotetext{
ABSTRACT

The objective of this work was to evaluate the potential of rooting and acclimatization of semi-

${ }^{1}$ Universidade Federal de Pelotas, Pelotas, RS, Brasil.

${ }^{2}$ Universidade Federal do Maranhão, São Luiz, MA, Brasil.

${ }^{3}$ Embrapa Clima Temperado, Pelotas, RS, Brasil.

*Autor para correspondência <birela89@gmail.com>
}

woody cuttings of different rootstocks of Prunus spp. (I-93-38, I-93-27, I-67-57-14, I-67-55-13) e Prunus persica (I-67-54-12), both originating in North America. Semihardwood cuttings were prepared with $15 \mathrm{~cm}$ maintaining a couple of whole leaves in the apical portion were conditioned in trays with fine vermiculite and kept under intermittent mist for 50 days. Cuttings ready to be transplanted were placed in 'citropotes' containing $2 \mathrm{~L}$ commercial Carolina ${ }^{\circledR}$ substrate and kept in acclimation for 60 days. It was observed that the percentage of rooted cuttings was higher for genotype I-93-27 (66.66\%), not differing from genotypes I-67-55-13, I-67-54-12 and I-67$57-14$, with $57.77 \%, 52.22 \%$ and $44.44 \%$ of rooted cuttings, respectively, this cultivar also recorded the average length of three major roots $(4.74 \mathrm{~cm})$ to the average number of roots per cutting, the highest values were observed in I-93-27 genotypes (20.35) and I-6757-14 (23.65). It was also observed that the average percentage of transplanted and acclimatized stakes were higher for genotype I-93-27 (72.22\%) compared to the others. The I-67-55-13 genotype showed better results for all variables, and more established plants after acclimatization.

KEYWORDS: Prunus persica, rooting, semihardwood cutting, indolbutíric acid.

\section{INTRODUÇÃO}

A fruticultura é uma atividade agrícola muito importante para o Brasil, representando uma grande fatia do PIB nacional, pela sua extensão continental o país possui clima para produzir frutas dos mais variados tipos, dentre estas estão as frutas de clima temperado, produzidas principalmente nas regiões sul e sudeste do Brasil. Nesses locais tem-se buscado 
constantemente a adoção de estratégias para aumentar a produção e a produtividade destas frutas, visando, principalmente, a diminuição das importações, uma vez que a produção nacional não consegue abastecer o mercado interno, especialmente em se tratando de frutíferas de caroço.

A produção, a produtividade e a qualidade das frutas estão intimamente relacionadas à qualidade das mudas (MAYER et al. 2014), e na fruticultura, como em outros setores econômicos, as novas tecnologias também são responsáveis pelos bons resultados agregados ao produto final (TOMAZ et al. 2014). Entretanto, a forma de propagação do pessegueiro na região Sul do Brasil é, tradicionalmente, realizada através da enxertia de borbulhas sobre os portaenxertos obtidos a partir de sementes provenientes de fábricas de conservas, as quais não possuem garantia de qualidade genética e sanitária (TOFANELLI et al. 2001).

Muito estudo vem tentando comprovar a importância da escolha do portaenxerto, devido à sua influência sobre o vigor da planta, qualidade do fruto e produtividade do pomar (PICOLOTTO et al. 2009, MAYER et al. 2014, RADMANN et al. 2014). Esta escolha deve ser baseada em alguns fatores, como o tipo de material a ser utilizado, pois atualmente ainda faltam estudos que comprovam quais portaenxertos são mais adequados para as diferentes condições de solo e clima do Brasil. Diante disso, pesquisas têm sido realizadas visando melhorar o sistema de obtenção de portaenxertos de pessegueiro em campo e em ambiente protegido (SCHMITZ et al. 2014, MAYER et al. 2014, RADMANN et al. 2014, TIMM et al. 2015).

A propagação vegetativa através de estaquia tem se mostrado uma alternativa viável, com baixo custo, rapidez no processo de produção de mudas para várias espécies, além de garantir a manutenção da homogeneidade do material vegetal, permitindo produzir mudas idênticas à planta-matriz, elevando a produtividade e a qualidade dos pomares (TIMM et al. 2015). Entretanto, a viabilidade de uso dessa técnica depende da capacidade de formação de raízes adventícias em cada espécie ou genótipo, da qualidade do sistema radicular formado e do desenvolvimento posterior da planta propagada na área de produção (FACHINELLO et al. 2005).

Visando melhorar as taxas de enraizamento e a qualidade do sistema radicular das estacas, a utilização de auxinas sintéticas, como o ácido indolbutírico
(AIB), têm se tornado uma prática necessária, uma vez que esse regulador de crescimento auxilia na indução da rizogênese e, além disso, é um dos reguladores de crescimento mais utilizados pela sua estabilidade e, mesmo em altas concentrações, não é tóxico (BETTONI et al. 2014). Nesse sentido, MINDÊLLO NETO et al. (2004), trabalhando com portaenxertos de pessegueiro, afirmam que a necessidade de aplicação de reguladores varia com as características genéticas do material, e que quanto mais jovens forem os tecidos do material a ser propagado, maiores serão os índices endógenos de auxina e menores os de giberelina, condição que segundo BOTELHO et al. (2005) favorece o enraizamento dos propágulos.

Diante disso, o objetivo deste trabalho foi avaliar o potencial de enraizamento e aclimatação de estacas semilenhosas de diferentes portaenxertos de Prunus spp. de origem norte americana.

\section{MATERIAL E MÉTODOS}

O trabalho foi conduzido em casa de vegetação, utilizando material vegetal proveniente de plantasmatrizes da "Coleção de portaenxertos de Prunus" da Embrapa Clima Temperado, mantida em condição de campo e sem irrigação.

Para o experimento foram utilizados os genótipos de origem norte americana de portaenxertos de pessegueiro I-93-38 e I-93-27 oriundos do estado do Texas e I-67-57-14, I-67-55-13 e I-67-54-12 oriundos do estado de Nova Jersey. As plantas matrizes foram submetidas à poda drástica no mês de julho, cortandose todas as pernadas a uma altura entre $1,0 \mathrm{~m} \mathrm{e} 1,2 \mathrm{~m}$, objetivando estimular intensa, vigorosa e padronizada brotação.

No mês de fevereiro do ano subsequente realizou-se a coleta de ramos semilenhosos, estes foram levados imediatamente para câmara de nebulização intermitente, instalada no interior de uma estufa agrícola tipo arco, $24 \mathrm{~m} \mathrm{x} 8 \mathrm{~m}$, com teto em polietileno transparente e laterais com tela antiafídeos. O sistema de nebulização foi coberto com tela refletora Aluminet Polysack retrátil, para reduzir a radiação solar.

Foram cortadas estacas com aproximadamente $0,7 \mathrm{~cm}$ de diâmetro e $15 \mathrm{~cm}$ de comprimento, contendo um par de folhas inteiras na parte apical, sendo a base cortada transversalmente (imediatamente abaixo de um nó) e, o ápice contado em bisel. Na base da estaca foram feitas duas lesões opostas $( \pm 3 \mathrm{~cm})$, a fim de 
expor o câmbio vascular. A base das estacas foi imersa em solução contendo $3.000 \mathrm{mg} \mathrm{L}^{-1}$ de AIB (Ácido Indol-3 Butírico), e posteriormente acondicionadas em caixas plásticas perfuradas, tamanho $50 \times 30$ x $18 \mathrm{~cm}$, contendo vermiculita com granulometria fina, mantidas em bancadas de ferro galvanizado. $\mathrm{O}$ sistema de nebulização intermitente foi controlado por temporizador, programado para nebulizar durante 10 segundos a cada intervalo de três minutos, durante todo o período de enraizamento (50 dias).

O delineamento experimental foi inteiramente casualizado, com seis repetições por genótipo, sendo a repetição composta por 30 estacas cada, e através de sorteio três repetições foram submetidas à avaliação das seguintes variáveis: porcentagem de estacas que apresentaram brotações, porcentagem de estacas vivas, porcentagem de estacas enraizadas, massa $(\mathrm{g})$ seca das brotações e das raízes, comprimento médio $(\mathrm{cm})$ das três maiores raízes e o número médio de raízes por estaca. As estacas que se apresentavam aptas para o transplantio foram colocadas em citropotes, contendo 2 L de substrato comercial Carolina ${ }^{\circledR}$ e mantidos em aclimatação por 60 dias quando foi avaliada a porcentagem de plantas estabelecidas.
Para a análise estatística, fez-se a transformação dos dados expressos em percentagem segundo o Arco Seno $(\mathrm{x} / 100)^{1 / 2}$ e dados de contagem para $\log \mathrm{x}+1$. Os dados foram submetidos à análise de variância, e as médias comparadas pelo teste de Tukey, a 5\% de probabilidade de erro, através do programa estatístico SISVAR (FERREIRA 2008).

\section{RESULTADOS}

Com base na análise de variância, verificou-se que as variáveis porcentagem de estacas enraizadas, comprimento médio das três maiores raízes, porcentagem de estacas com brotações, comprimento médio das brotações, massa seca das brotações e número de plantas estabelecidas tiveram efeito significativo para o fator cultivar.

A porcentagem de estacas enraizadas foi maior para o genótipo I-93-27 (66,66\%), não diferindo dos genótipos I-67-55-13, I-67-54-12 e I-67-5714 , com $57,77 \%, 52,22 \%$ e $44,44 \%$ de estacas enraizadas, respectivamente. A menor porcentagem de enraizamento foi verificada no genótipo I-93-38, onde somente 13,33\% das estacas enraizaram (Tabela $1)$.

Tabela 1. Efeito do genótipo dos porta enxertos de pessegueiro (P. persica) na porcentagem de estacas enraizadas, porcentagem de estacas vivas, número de raízes por estaca, comprimento das três maiores raízes e massa seca das raízes, no enraizamento de estacas semilenhosas, com utilização de AIB. EMBRAPA Clima Temperado, UFPEL, 2015.

Table 1. Effect of the peach rootstock genotype (P. persica) on the percentage of rooted cuttings, percentage of live cuttings, number of roots per cutting, length of the three largest roots and root dry mass, on rooting of semilenous cuttings, using of AIB. EMBRAPA Temperate Climate, UFPEL, 2015.

\begin{tabular}{lccccc}
\hline & \multicolumn{5}{c}{ Variáveis } \\
\cline { 2 - 6 } Genótipo & $\begin{array}{c}\text { \% Estacas } \\
\text { enraizadas }\end{array}$ & $\begin{array}{c}\text { Número de } \\
\text { raízes por } \\
\text { estaca }\end{array}$ & $\begin{array}{c}\text { Comprimento } \\
\text { médio das três } \\
\text { maiores raízes }\end{array}$ & $\begin{array}{c}\text { Massa } \\
\text { seca das } \\
\text { raízes }\end{array}$ & $\begin{array}{c}\text { \% Estacas } \\
\text { vivas }\end{array}$ \\
\hline I-93-38 & $13,33 \mathrm{~b}$ & $14,00 \mathrm{a}$ & $3,09 \mathrm{ab}$ & $0,27 \mathrm{a}$ & $15,55 \mathrm{~b}$ \\
I-93-27 & $66,66 \mathrm{a}$ & $20,35 \mathrm{a}$ & $4,74 \mathrm{a}$ & $1,83 \mathrm{a}$ & $73,33 \mathrm{a}$ \\
I-67-57-14 & $44,44 \mathrm{ab}$ & $23,65 \mathrm{a}$ & $4,00 \mathrm{ab}$ & $1,25 \mathrm{a}$ & $56,66 \mathrm{ab}$ \\
I-67-55-13 & $57,77 \mathrm{ab}$ & $15,76 \mathrm{a}$ & $1,88 \mathrm{~b}$ & $0,50 \mathrm{a}$ & $63,32 \mathrm{ab}$ \\
I-67-54-12 & $52,22 \mathrm{ab}$ & $17,34 \mathrm{a}$ & $3,22 \mathrm{ab}$ & $0,81 \mathrm{a}$ & $59,99 \mathrm{ab}$ \\
\hline CV \% & 24,99 & 19,48 & 30,29 & 76,21 & 22,74 \\
Média & 0,06 & 1,22 & 3,38 & 0,93 & 0,07 \\
\hline
\end{tabular}

Médias seguidas pela mesma letra na coluna não diferem pelo teste de Tukey $(\alpha=0,05)$. 
O comprimento médio das três maiores raízes foi maior no genótipo I-93-27, que apresentou raízes com uma média de $4,74 \mathrm{~cm}$ de comprimento. Para essa variável as menores raízes foram observadas no I-67-55-13, com uma média de 1,88 cm. Apesar dessa diferença entre o tamanho das raízes, o número de raízes por estaca e a massa seca das raízes não diferenciou estatisticamente entre os genótipos (Tabela 1). Mesmo não havendo diferença, a massa seca das raízes do genótipo I-93-27 foi maior (1,82 g), representando $31,7 \%$ mais massa seca em relação ao genótipo I-67-57-14. O genótipo I-93-27 apresentou a maior porcentagem de estacas vivas, diferindo somente em relação ao genótipo I-93-38, que por sua vez, apresentou somente $13,33 \%$ das estacas enraizadas, o menor número de raízes por estaca $(14,0)$ e a menor massa seca das raízes $(0,27 \mathrm{~g})$.

Considerando a maior porcentagem de estacas enraizadas e sobreviventes, o genótipo com maior porcentagem de estacas transplantadas foi o I-93-27 (72,22\%), tendo em média $42,36 \%$ mais estacas transplantadas que os demais. Entretanto, este genótipo apresentou porcentagem de plantas estabelecidas nula $(0,0 \%)$, ou seja, todas as estacas morreram após o transplante. Os melhores resultados para o número de plantas estabelecidas foram obtidos pelo genótipo I-67-55-13, com 16,66\% das plantas estabelecidas, que foi superior somente em relação aos genótipos I-93-27 e I-93-38 (Tabela 2).

Em relação aos parâmetros avaliados na parte aérea após o período de enraizamento, foram obtidas $58,77 \%$ de estacas com brotações no genótipo I-67-55-13, com uma média de 1,77 brotações, onde o comprimento médio dessas brotações foi de $3,2 \mathrm{~cm}$, apresentando a maior massa seca das brotações $(0,66 \mathrm{~g})$. O genótipo que apresentou o menor número de estacas brotadas foi I-93-27, com 1,00 brotação contendo 1,21 cm de comprimento, sendo as menores brotações quando comparado aos demais genótipos, com massa seca de $0,08 \mathrm{~g}$ (Tabela 3).

\section{DISCUSSÃO}

Com base nos resultados obtidos, verificou-se que as respostas das estacas ao enraizamento, variaram em função do genótipo, conforme pode ser observado na Tabela 1. Para que ocorra um enraizamento bem sucedido, é necessário que os tecidos das plantas doadoras e a estrutura interna de seus caules forneçam as condições primordiais necessárias, pois o processo de formação dos primórdios de raízes adventícias em estacas caulinares podem ter diferentes origens histológicas (JESUS et al. 2010). Segundo FAHN (1990), raízes adventícias podem se desenvolver a partir do desenvolvimento do meristema primário dos caules.

Existem plantas com diferentes habilidades de formação e estrutura de raízes adventícias, bem como a sua sequência de desenvolvimento. Segundo JESUS et al. (2010), muitas espécies lenhosas possuem um anel contínuo de esclerênquima entre o floema e o córtex, externamente ao ponto de origem das raízes adventícias, constituindo uma barreira anatômica ao enraizamento, que é agravado com a maturidade do tecido.

No presente estudo, foram utilizadas estacas semilenhosas, onde os tecidos se apresentam mais amadurecidos, sendo possível perceber que a porcentagem média de enraizamento $(46,8 \%)$ apresentou-se inferior a $70 \%$, valor de referência, que considera a propagação vegetativa satisfatória (CHAGAS et al. 2008, CARDOSO et al. 2011, RADMANN et al. 2014) entretanto, quando comparamos os dados aqui apresentados, com os de outros autores, notamos que, em média, a porcentagem de enraizamento obtida foi satisfatória. CARDOSO et al. (2011), ao testarem o enraizamento de estacas semilenhosas do porta enxerto de pessegueiro 'Okinawa', tratadas com $2.000 \mathrm{mg} \mathrm{L}^{-1}$ de AIB, em substrato vermiculita, obtiveram uma média de $26,7 \%$ de estacas enraizadas, entretanto RADMANN et al. (2014) ao testar o enraizamento de estacas semilenhosas de genótipos de portaenxerto de pessegueiro, obtiveram uma média $51,8 \%$ de estacas enraizadas.

Sabe-se que a potencialidade de uma estaca em formar raízes é variável com a espécie e também com a cultivar, e que a variação no número e comprimento de raízes indica, que os fatores de enraizamento e crescimento, como, por exemplo, concentração de açúcares e hormônios, endógenos nos tecidos, também atuam de forma diferenciada entre as cultivares (FACHINELLO et al. 2005, VIGNOLO et al. 2014). De acordo com MOUBAYIDIN et al. (2010), o crescimento das raízes ocorre quando, no meristema apical, a divisão celular prevalece sobre a diferenciação, fato ocasionado porque há uma maior concentração de auxinas promovendo a divisão, do que de citocininas promovendo a diferenciação. 
Tabela 2.Efeito do genótipo dos porta enxertos de pessegueiro ( $P$. persica) na porcentagem de estacas transplantadas e porcentagem de plantas estabelecidas, de estacas semilenhosas, após período de aclimatização. EMBRAPA Clima Temperado, UFPEL, 2015.

Table 2. Effect of the genotype of the peach rootstocks (P. persica) on the percentage of transplanted cuttings and percentage of established plants, of semilenous cuttings, after acclimatization period. EMBRAPA Temperate Climate, UFPEL, 2015.

\begin{tabular}{lcc}
\hline & \multicolumn{2}{c}{ Variáveis } \\
\cline { 2 - 3 } Cultivares & $\begin{array}{c}\text { Porcentagem de estacas } \\
\text { transplantadas }\end{array}$ & $\begin{array}{c}\text { Porcentagem de plantas } \\
\text { estabelecidas }\end{array}$ \\
\hline I-93-38 & $23,33 \mathrm{a}$ & $1,11 \mathrm{~b}$ \\
I-93-27 & $72,22 \mathrm{a}$ & $0 \mathrm{~b}$ \\
I-67-57-14 & $31,10 \mathrm{a}$ & $2,22 \mathrm{ab}$ \\
I-67-55-13 & $55,55 \mathrm{a}$ & $16,66 \mathrm{a}$ \\
I-67-54-12 & $56,66 \mathrm{a}$ & $5,55 \mathrm{ab}$ \\
\hline CV (\%) & 74,65 & 70,25 \\
Média & 1,33 & 0,08
\end{tabular}

Médias seguidas pela mesma letra na coluna não diferem pelo teste de Tukey $(\alpha=0,05)$.

Tabela 3. Efeito do genótipo dos porta enxertos pessegueiro ( $P$. persica) na porcentagem de estacas com brotações, comprimento médio das brotações, massa seca das brotações e número de brotações no enraizamento de estacas semilenhosas. EMBRAPA Clima Temperado, UFPEL, 2015.

Table 3. Effect of genotype of peach rootstocks (P. persica) on the percentage of cuttings with sprouts, average length of shoots, shoot dry mass and number of shoots in the rooting of semilenous cuttings. EMBRAPA Temperate Climate, UFPEL, 2015.

\begin{tabular}{lcccc}
\hline \multirow{2}{*}{ Cultivares } & \multicolumn{4}{c}{ Variáveis } \\
\cline { 2 - 5 } & $\begin{array}{c}\text { \% Estacas com } \\
\text { brotações }\end{array}$ & $\begin{array}{c}\text { Comprimento das } \\
\text { brotações }(\mathrm{cm})\end{array}$ & $\begin{array}{c}\text { Massa das } \\
\text { brotações }(\mathrm{g})\end{array}$ & $\begin{array}{c}\text { Número de } \\
\text { brotações }\end{array}$ \\
\hline I-93-38 & $22,21 \mathrm{ab}$ & $2,66 \mathrm{ab}$ & $0,06 \mathrm{~b}$ & $1,16 \mathrm{a}$ \\
I-93-27 & $4,44 \mathrm{~b}$ & $1,21 \mathrm{~b}$ & $0,08 \mathrm{~b}$ & $1,00 \mathrm{a}$ \\
I-67-57-14 & $22,21 \mathrm{ab}$ & $2,38 \mathrm{ab}$ & $0,17 \mathrm{~b}$ & $1,38 \mathrm{a}$ \\
I-67-55-13 & $58,77 \mathrm{a}$ & $3,22 \mathrm{a}$ & $0,65 \mathrm{a}$ & $1,77 \mathrm{a}$ \\
I-67-54-12 & $18,88 \mathrm{ab}$ & $2,58 \mathrm{ab}$ & $0,12 \mathrm{~b}$ & $1,33 \mathrm{a}$ \\
\hline CV (\%) & 29,28 & 26,82 & 74,93 & 73,66 \\
Média & 0,04 & 2,41 & 0,21 & 0,24 \\
\hline
\end{tabular}

Médias seguidas pela mesma letra na coluna não diferem pelo teste de Tukey $(\alpha=0,05)$. 
Desta forma, foi possível observar, neste ensaio, que apesar de não ter havido diferença significativa, quando analisadas as variáveis referentes aos padrões de enraizamento (número de raízes por estaca, comprimento das três maiores raízes, massa seca das raízes), pode-se notar uma forte influência genética, pois o genótipo I-93-27 sobressaiu aos demais (Tabela $1)$.

Nesse sentido, podemos ressaltar que as dificuldades de enraizamento de estacas constituem um dos maiores entraves da propagação vegetativa em Prunus spp., envolvendo vários fatores, como a predisposição genética ao enraizamento, condição fisiológica da planta matriz e o balanço hormonal, entre outros fatores, podemos também ressaltar, que a formação de raízes laterais também é regulada antagonicamente pela relação auxinas/citocininas (FACHINELLO et al. 2005, VERNIER \& CARDOSO 2013), fato que justifica a utilização de auxina sintética exógenas. De acordo com BASTOS et al. (2009) o AIB é a auxina sintética mais utilizada, pois é altamente efetiva no estímulo ao enraizamento, devido à sua menor mobilidade, menor fotossensibilidade e maior estabilidade química na planta. Além disso, o AIB, por ser estável à fotodegradação e possuir boa capacidade de promover o enraizamento, tem sido empregado em estacas de várias espécies, especialmente aquelas que apresentam dificuldade em emitir raízes (VERNIER \& CARDOSO 2013). Sendo assim, aplicações exógenas de auxina sintética podem acelerar o processo de enraizamento, melhorar a qualidade das raízes formadas e, consequentemente, produzir mudas com uniformidade.

$\mathrm{Na}$ produção de mudas em escala comercial, o sistema radicular bem formado favorece a absorção de nutrientes e água, propiciando, desta forma, um melhor desenvolvimento da muda quando transplantada (CARDOSO et al. 2011). No ensaio realizado, foi observado que o genótipo I-93-27, que apresentou maior emissão e comprimento das raízes, teve o maior número de estacas transplantadas (Tabela 1), entretanto, apresentou o pior índice de plantas estabelecidas. Já o genótipo I-67-55-13, diferiu estatisticamente do genótipo anterior, apenas para a variável comprimento das raízes, apresentando a menor média de todos os genótipos analisados, e apesar disso, teve o maior índice de plantas estabelecidas (Tabela 1). Desta forma, podemos evidenciar que o gasto energético que o genótipo I-9327 teve em produzir raízes mais longas não garantiu a qualidade das mesmas e a sua capacidade de estabelecimento. Com relação à qualidade do sistema radicular, MAYER \& PEREIRA (2003) salientam que se deve buscar um equilíbrio entre o número de raízes formadas e o comprimento destas. RADMANN et al. (2014) também enfatiza que é necessário que haja um equilíbrio entre o número e o comprimento das raízes, pois estas características que são muito importantes para aumentar as chances de sobrevivência e para o melhor desenvolvimento das mudas na fase após o transplantio.

Para as variáveis relativas ao desenvolvimento da parte aérea das estacas, observou-se forte efeito do fator genótipo, onde estacas advindas do genótipo I-67-55-13, apresentaram a maior porcentagem de brotações, o maior número de brotos por estaca e a maior massa seca da parte aérea (Tabela 3). Resultados semelhantes foram obtidos por RADMANN et al. (2014), que verificaram efeito significativo apenas do fator cultivar para a porcentagem de estacas brotadas.

De acordo com PACHECO \& FRANCO (2008), devido às folhas e brotações serem locais de síntese de auxina e carboidratos, espera-se que a presença destas estruturas favoreça a sobrevivência e a formação de raízes. Além disso, é provável que o enraizamento e a sobrevivência das estacas, nestas condições, estejam relacionados à síntese de compostos fenólicos pela parte aérea, pois estudos sugerem que certos compostos fenólicos, como é o caso do ácido cafeico, catecol e clorogênico, interagem com as auxinas, induzindo a iniciação das raízes (VIGNOLO et al. 2014).

Os resultados deste ensaio também demonstraram que o genótipo I-67-55-13, além de ter os melhores índices para os dados relativos à parte aérea, também apresentou a maior porcentagem de plantas estabelecidas após o transplantio. De acordo com CHAGAS et al. (2008) isso pode ocorrer pois a emissão simultânea de raízes e brotações, favorece o desenvolvimento das estacas, facilitando o crescimento e o estabelecimento posterior das mesmas. Além disso, a presença de brotações exerce forte influência estimulante sobre o enraizamento da estaca, pois permite a sobrevivência pela síntese de carboidratos por meio da fotossíntese, os quais atuam como fonte de energia e como elementos constitutivos para as novas células formadas, além do fornecimento de auxinas e outras substâncias importantes para a atividade cambial e a diferenciação celular (HAISSIG 


\section{\& DAVIS 1994).}

Neste contexto, verificou-se que o sucesso da propagação de porta enxertos para a produção de mudas em escala comercial está associado à escolha da cultivar a ser propagada, e que a avaliação de cada genótipo em particular, bem como o controle das condições do ambiente de enraizamento são fundamentais para o sucesso da propagação por estaquia sem variabilidade genética, ao contrário do que ocorre na propagação por sementes.

\section{CONCLUSÃO}

O genótipo I-93-27 apresenta o maior potencial de enraizamento quando comparado aos demais genótipos avaliados, contudo, o genótipo I-67-5513 destaca-se quanto aos parâmetros referentes à parte aérea, e apresenta o maior número de plantas estabelecidas.

\section{REFERÊNCIAS}

BASTOS DC et al. 2009. Estiolamento, incisão na base da estaca e uso do ácido indolbutírico na propagação da caramboleira por estacas lenhosas. Ciência e Agrotecnologia 33: 313-318.

BETTONI JC et al. 2014. Indução do enraizamento em estacas lenhosas do porta-enxerto de videira VR043-43 submetidas a lesões e aplicação de auxinas. Evidência 14: 129-138.

BOTELHO RV et al. 2005. Efeitos de reguladores vegetais na propagação vegetativa do porta-enxerto de Videira '4343' (Vitis vinifera $\mathrm{x}$ V. rotundifolia). Revista Brasileira de Fruticultura 27: 6-8.

CARDOSO C et al. 2011. AIB e substratos no enraizamento de estacas de pessegueiro 'Okinawa' coletadas no outono. Semina: Ciências Agrárias 32: 1307-1314.

CHAGAS EA et al. 2008. Enraizamento de estacas lenhosas de pessegueiro e clones de umezeiros submetidos à aplicação de AIB. Ciência e Agrotecnologia, 32: 986-991. FACHINELLO JC et al. 2005. Propagação de plantas frutíferas. Brasília, DF: Embrapa Informação Tecnológica. $221 \mathrm{p}$.

FAHN A. 1990. Plant anatomy. 4.ed. Oxford: Pergamon Press. 588p.

FERREIRA DF. 2008. SISVAR: um programa para análises e ensino de estatística. Revista Symposium 6: 36-41.

HAISSIG BE \& DAVIS TD. 1994. A historical evaluation of adventitious rooting research to 1993. In: DAVIS TD \& HAISSIG BE. (Eds.). Biology of adventitious roots formation. p. 275-331.

JESUS MAS et al. 2010. Observações anatômicas em plantas de Coffea arabica L. obtidas por enraizamento de estacas. Revista Ceres 57: 175-180.

MAYER NA \& PEREIRA FM. 2003. Enraizamento de estacas herbáceas de quatro clones de umezeiro (Prunus mume Sieb. et Zucc.) durante o inverno ameno, em Jaboticabal-SP. Revista Brasileira de Fruticultura 25: 505507.

MAYER NA et al. 2014. Estaquia herbácea de portaenxertos de pessegueiro no final do verão. Semina: Ciências Agrárias 35: 1761-1772.

MINDÊLLO NETO UR et al. 2004. Efeito do ácido indolbutírico no enraizamento de estacas herbáceas de dois porta-enxertos de pessegueiro. Revista Brasileira de Agrociência 10: 433-437.

MOUBAYIDIN L et al. 2010. The rate of cell differentiation controls the arabidopsis root meristem growth phase. Current Biology 20: 1138-1143.

PACHECO JP \& FRANCO ETH. 2008. Substratos e estacas com e sem folhas no enraizamento de Luehea divaricata Mart. Ciência Rural 38: 1900-1906.

PICOLOTTO L et al. 2009. Características vegetativas, fenológicas e produtivas do pessegueiro cultivar Chimarrita enxertado em diferentes porta-enxertos. Pesquisa Agropecuária Brasileira 44: 583-589.

RADMANN EB et al. 2014. Interação entre o genótipo e AIB no enraizamento de estacas semilenhosas de portaenxertos de pessegueiro. Nativa 2: 229-233.

SCHMITZ JD et al. 2014. Desempenho de porta-enxertos em diferentes sistemas de cultivo na produção de mudas do pessegueiro 'Chimarrita'. Revista Ceres 61: 155-160.

TIMMCRF et al. 2015. Enraizamento de miniestacas a partir de ramos herbáceos de porta-enxertos de pessegueiro, em diferentes substratos. Revista Inova Ciência \& Tecnologia 1: $18-22$.

TOMAZ ZFP et al. 2014. Desenvolvimento de portaenxertos de pessegueiro obtidos de miniestacas, em duas épocas, e sistema de cultivo sem solo. Revista Brasileira de Fruticultura 36: 988-995.

TOFANELLI MBD et al. 2001. Capacidade de enraizamento de estacas lenhosas e semilenhosas de cultivares de pessegueiro. Ciência e Agrotecnologia 25: 840-847.

VERNIER RM \& CARDOSO SB. 2013. Influência do ácido indol-butírico no enraizamento de estacas em espécies frutíferas e ornamentais. Revista Eletrônica de Educação e Ciência 3: 11-16.

VIGNOLO GK et al. 2014. Presença de folhas no enraizamento de estacas de amoreira-preta. Ciência Rural 44: 467-472. 